\title{
COLLISION SAFETY COMPARISON OF CONVENTIONAL AND CRASH ENERGY MANAGEMENT PASSENGER RAIL CAR DESIGNS
}

\author{
Kristine J. Severson \\ David C. Tyrell \\ Volpe National Transportation Systems Center \\ U.S. Department of Transportation \\ Cambridge, MA 02142
}

\author{
A. Benjamin Perlman \\ Tufts University \\ Department of Mechanical Engineering \\ Medford, MA 02155
}

\section{ABSTRACT}

In conjunction with full-scale equipment tests, collision dynamics models of passenger rail cars have been developed to investigate the benefits provided by incorporating energyabsorbing crush zones at the ends of the cars. In a collision, the majority of the structural damage is generally focused at the point of impact for cars of conventional design. In contrast, cars with crush zones, or crash energy management (CEM), can better preserve occupied areas by distributing crush to the ends of cars.

Impact tests of conventional equipment have already been conducted, which consisted of a single car and two coupled cars colliding with a rigid wall. Corresponding tests are planned using CEM equipment. This paper presents preliminary predictions of the one- and two-car CEM tests, and compares them to the results of the respective conventional equipment tests. The comparison will focus on loss of occupant volume, secondary impact velocity (SIV), and lateral buckling, as measures of occupant protection.

The modeling results indicate that the occupant volume can be preserved in both the one-car and two-car tests of the CEM equipment, while $2 \frac{1}{2}$ and 3 feet of occupant volume were crushed in the respective tests of conventional equipment. In the two-car model, the CEM design is able to distribute the crush between both cars, whereas the conventional design incurs nearly all the crush at the point of impact.

The CEM design can absorb more energy without crushing the occupied area because it requires a higher average force per foot of crush at the vehicle ends. The trade-off associated with this higher crush force is generally a higher SIV for occupants in the CEM cars. Secondary impact velocity refers to the velocity at which an occupant strikes some part of the interior, in this analysis the back of the seat ahead of the occupant. The greatest SIV penalty is in the impacting car. The difference between the SIV for cars in a conventional and a CEM consist decreases in each trailing car. That is, the SIV generally decreases in each trailing car of a CEM consist, while the SIV remains approximately the same in each trailing car of a conventional consist.

\section{INTRODUCTION}

Conventional passenger rail cars are designed to have a minimum static end strength of $800,000 \mathrm{lbs}$, when applied at the line of draft. A passenger rail car structure must be able to support a longitudinal static compressive load of 800,000 lbs applied at the buff stops without permanent deformation. (The buff stops longitudinally support the draft gear, which in turn supports the coupler. They are located approximately six feet inboard from end of the car and approximately nine inches under the floor.) Under dynamic loading conditions cars of this design generally require a force around 1.5 million pounds to initiate buckling of the draft sill. After the draft sill buckles during a collision, crushing continues from front to rear at a significantly lower force. In a collision, cars of this design generally incur the most damage at the point of impact.

In contrast, cars designed with CEM have multiple tiers, or zones, of increasing crush force at the ends of the cars. These sacrificial crush zones are designed to crush in a successive manner, absorbing collision energy in unoccupied car ends before crushing the occupied areas inboard of the crush zones. The weaker crush zones allow the absorption of collision energy to be shared by multiple cars throughout the consist. This sharing of energy absorption also helps to keep the cars inline, rather than buckling laterally or vertically. Large amplitude buckling may cause more occupant injury or fatality due to secondary impacts between the occupant and parts of the vehicle interior.

The concept of CEM in rail cars is not new. During the 1990s the French and British designed, built, and tested rail cars with CEM [1, 2, 3] and achieved successful results. However, research and testing is required to design cars with CEM that perform successfully in the U.S. due to the different operating environment. In the U.S., passenger rail cars generally have to share the track with more and heavier freight trains than in Europe. This traffic mix requires cars to have a 
different force/crush characteristic that allows the cars to absorb more energy in a collision.

Modeling results indicate that CEM can significantly improve occupant survivability in train collisions. A series of six tests have been planned to prove the effectiveness of this concept (see Table 1). The first three tests using conventional equipment have been completed. The results of these tests show that nearly all the structural damage is focused on the leading passenger car, and in the case of the train-to-train test with significant loss of occupant volume. The next three tests will measure the response of CEM equipment under the same conditions used to test the conventional equipment.

Table 1. Full-Scale Impact Tests

\begin{tabular}{|c|c|}
\hline Test Conditions & $\begin{array}{c}\text { Equipment } \\
\text { Type }\end{array}$ \\
\hline $\begin{array}{c}\text { One-car impact } \\
\text { with rigid wall }(11 / 16 / 99)[4]\end{array}$ & \multirow{3}{*}{$\begin{array}{l}\text { Conventional } \\
\text { Equipment }\end{array}$} \\
\hline Two-car impact with rigid wall $(4 / 4 / 00)$ [5] & \\
\hline $\begin{array}{c}\text { Cab car-led train impact with } \\
\text { locomotive-led train }(1 / 31 / 02)[6]\end{array}$ & \\
\hline One-car impact with rigid wall & \multirow{3}{*}{$\begin{array}{l}\text { Modified } \\
\text { Equipment }\end{array}$} \\
\hline Two-car impact with rigid wall & \\
\hline $\begin{array}{l}\text { Cab car-led train impact with } \\
\text { locomotive-led train }\end{array}$ & \\
\hline
\end{tabular}

The primary objectives of the test program are three-fold. The first objective is to measure the collision behavior of existing equipment. In order to quantify improvements in crashworthiness with CEM equipment, a better understanding of the performance of current equipment under impact conditions is needed. The second objective is to measure the collision behavior of modified equipment. Before CEM is implemented in rail cars, the effectiveness must be demonstrated. The third objective is to validate the computer models, so they can be used as tools to assist in developing test plans as well as CEM design. Collectively, these three objectives will help to meet the larger goal of improving rail collision safety for passengers and operators.

Prior to testing of the conventional equipment, several models were used to help develop the test requirements. First, a finite element (FE) model was developed to estimate the force/crush behavior of a conventional passenger car. Next, a collision dynamics (CD) model was created, using the force/crush behavior calculated in the FE model to evaluate the gross motion of the car. The results of the CD model were used to estimate the severity of the secondary impact during the collision. The cumulative results were used to size and place the instrumentation and to determine the impact speed for the tests. The models were also useful in interpreting the test data. As each test was completed, the models were fine-tuned to better agree with the test data.

These CD models validated against the conventional test conditions have been used to analyze the upcoming CEM equipment tests. The force/crush behavior in the CD model was based on preliminary finite element analysis of the modified CEM equipment. The results of the CD model have been used to predict the severity of the secondary impact environment for the modified equipment.

This paper compares the one-car and two-car models of conventional equipment (validated post-test) with estimates of the crashworthiness performance anticipated in the upcoming respective tests using equipment modified to incorporate CEM. The comparison will focus on loss of occupant volume and SIV as measures of occupant protection.

\section{BACKGROUND}

The first series of three tests, using existing equipment built to North American equipment standards, established a baseline of crashworthiness for conventional equipment. All tests were conducted at the FRA's Transportation Test Center in Pueblo, $\mathrm{CO}$. The one- and two-car tests will be described briefly in this paper. For more detail, see References [4, 5].

The first test was performed on Nov. 16, 1999, and consisted of a single commuter rail car impacting a rigid barrier at $35 \mathrm{mph}$. The collision speed was chosen in order to crush the car by a large amount - a reduction in car length of at least three feet - because there were uncertainties in the finite element analysis associated with large amounts of crush. The kinetic energy in the test was about 3 million ft-lbs.

The one-car test focused on the behavior of a single car. The objectives were to measure the force/crush characteristic, to observe failure modes of the major structural components, to measure the rigid body motions of the car, and to evaluate selected occupant protection strategies. The data collected during the test was used to improve the fidelity of the finite element and the collision dynamics models.

The occupant environment in the one-car test was severe. The energy absorbed in the test was equivalent to the energy absorbed in a collision between one car moving at $70 \mathrm{mph}$ and a stationary car. The maximum crush was about 5.4 feet, with all the visible damage occurring at the impacting end of the car. The secondary impact velocity was about $23 \mathrm{mph}$ for test dummies in forward-facing seats. The test and collision dynamics model results compared well in terms of total crush, energy absorbed and SIV.

The second test was performed on April 4, 2000, and consisted of two coupled commuter rail cars impacting a rigid barrier at $26 \mathrm{mph}$. The impact speed was chosen in order to achieve the same amount of structural damage to the impacting car as in the one-car test. The kinetic energy in this test was the same as in the one-car test ( $\sim 3$ million ft-lbs.).

The two-car test had the same objectives as the one-car test, with the additional goal of learning more about the coupled carto-car interaction and the conditions that lead to car buckling. Data was collected to measure the gross motion of the car bodies, the force/crush behavior at the point of impact, and the interaction between the cars. The measurements taken during the test are currently being used to improve and validate the two-car CD model. 
While the kinetic energy was the same in both tests, the collision was less severe in the two-car test, in terms of SIV. The trailing car pushing on the lead car served to minimize the acceleration of the lead car, which in turn reduced the SIV for the occupants. While the lead car was decelerating due to the impact with the rigid wall, the trailing car was simultaneously trying to accelerate the lead car.

The maximum crush at the point of impact was 6.2 feet. There was little damage at the coupled connection between the cars. The two cars remained coupled during the test, but buckled in a saw-tooth mode. Saw-tooth buckling is a term used to describe cars that translate laterally with respect to one another, until the ends of the cars come into contact. Saw-tooth buckling is a precursor to the more catastrophic large amplitude lateral buckling. The maximum lateral displacement between the cars during the collision was approximately 30 inches, with a final lateral displacement of 15 inches following the test. The secondary impact velocities were about $16 \mathrm{mph}$ for test dummies seated in forward-facing seats in both cars.

The significant results from the one- and two-car tests occurred similarly in train to train test, namely that nearly all of the crush was isolated at the point of impact, and that several of the cars buckled laterally in a saw-tooth mode.

The second series of tests will examine the feasibility of incorporating CEM in U.S. passenger trains. The tests will be conducted on existing equipment that has been modified to provide controlled energy absorption in the structures at the ends of the vehicles. Prototypes of the energy-absorbing components have been designed and fabricated, and are undergoing component testing to insure that they perform as desired under dynamic loading conditions [7].

During the two-car test of the modified CEM equipment, it is expected that the structural damage will be limited to 3 feet at the front end of the impacting vehicle and less than 1.5 feet on each car at the coupled connection. The cars are expected to remain upright with no lateral or vertical buckling. The secondary impact velocity is expected to be significant, but this effect would be reduced in a train collision involving more cars.

This paper presents CD model results from the one- and two-car conventional tests (validated against the test conditions), and compares these results to analytical predictions of the comparable tests using equipment designed to absorb collision energy in a predicable manner. This comparison will demonstrate the improvement in collision protection provided to passengers and operators. Refer to Appendix A for more detail on the approach used to model the test conditions.

\section{COMPARISON OF CONVENTIONAL AND CEM ANALYSIS RESULTS}

The primary target in the CEM one-car test is to limit the crush to 3 feet at the end of the car. The primary targets in the CEM two-car test are to limit the crush to 3 feet at the end of each car, and to keep the cars from buckling laterally. In this paper, car crush is used as a measure of passenger safety. Loss of occupant volume is based on crush of the occupied areas of the car. For this analysis, it is assumed that there are three feet of unoccupied area at each car end. If more than three feet are crushed at either end, then loss of occupant volume occurs. The goal then is to absorb the collision energy without crushing more than three feet at the car ends.

Secondary impact velocity is also used as a measure of occupant safety in this paper. SIV refers to the velocity at which an occupant strikes some part of the interior, in this case the forward seat back. The SIV is calculated as the occupant's velocity relative to the vehicle interior when the occupant's head has traveled 2.5 feet. This is approximately the distance between the occupant's head and the forward seat, when seated in forward-facing rows of seats that are placed 42 inches apart. This is a common seating configuration used in intercity passenger trains.

Figure 1 is a plot of the assumed force/crush behaviors used in the conventional and CEM models. In the conventional curve, a large initial force is required to initiate buckling/crushing of the draft sill. Once the draft sill buckles, crushing continues at a much lower force. After about 1 foot of crush of the coupler/draft sill, the car body makes contact with the rigid wall. An increase in the collision force is required to initiate crushing of the side sills, roof sills and body panels. Once buckling of these members is initiated, the force drops off again. The majority of the strength of the end structure comes from the draft sill. The side sills and roof sills carry a smaller portion of the load. When the draft sill buckles early on, it cannot maintain a significant load. This force/crush behavior is similar to the quasi-static force/crush behavior of a beam with uniform cross-section [8].

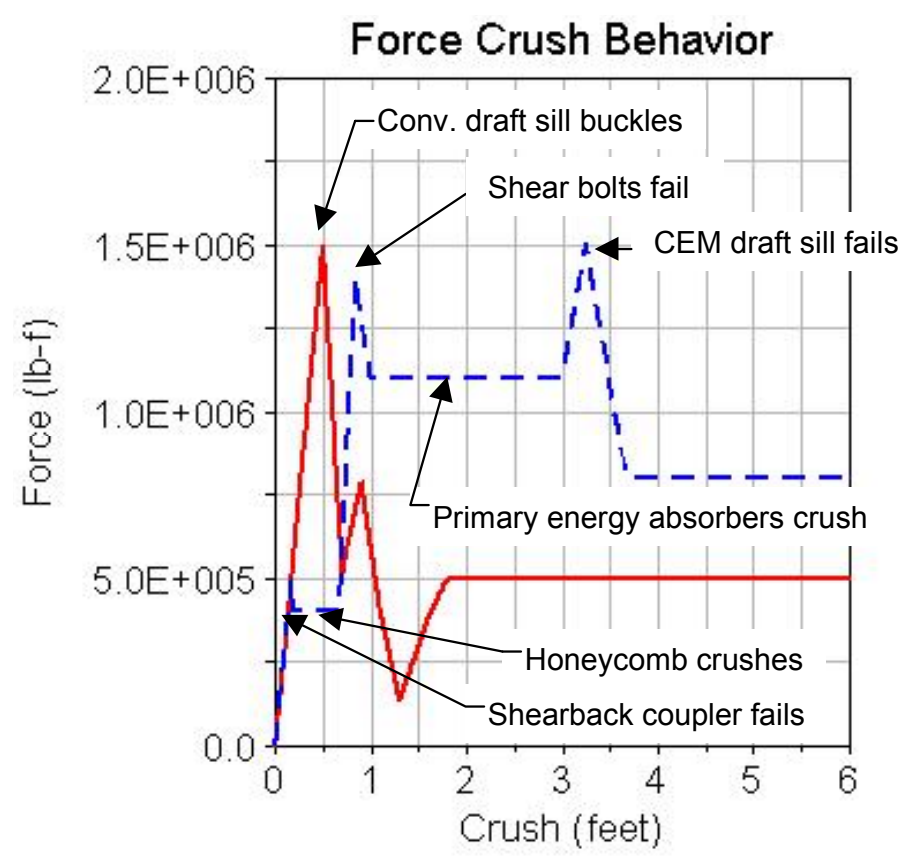

Figure 1. Force/Crush Behavior for Conventional and CEM design 
The candidate design to be used in the CEM tests is based on a sliding sill concept [7]. The force/crush curve corresponding to this design is characterized by a monotonic increase in force as the energy absorbers crush at the end(s) of the car. The initial slope is due to the loading of the shear back coupler. Once it fails, a block of aluminum honey comb is loaded, resulting in a constant crush load of 400,000 lbs. over about 8 inches. Next, the crush load is transferred to the end beams. At 1.4 million lbs. another set of shear bolts fail, and the primary energy absorbers are loaded. These absorbers are made up of two double box members, one on either side of the draft sill. The double box sections will crush about two feet under a 1.1 million pound load.

At the vehicle ends, the CEM design has a higher average force per foot of crush than that of the conventional design, thus it can absorb the same amount of collision energy while incurring less crush. The higher average force in the CEM design results in a higher average acceleration of the car body, which results in a higher SIV for the occupants. This trade-off between distance crushed and SIV is magnified in the one-car test where there are no other cars to participate in the energy absorption.

Car crush and SIV from the one-car and two-car analyses are compared in this section. For additional analysis results, refer to Appendix B.

\section{One-Car Test}

Figure 2 compares the car crush calculated with the one-car conventional and CEM models. In this $35 \mathrm{mph}$ test, the conventional design resulted in 5.6 feet of crush, which would cause 2.5 feet of crushed occupant volume. In contrast, the CEM model predicts less than 3.1 feet of crush under the same collision conditions, basically preventing penetration of the occupied area.

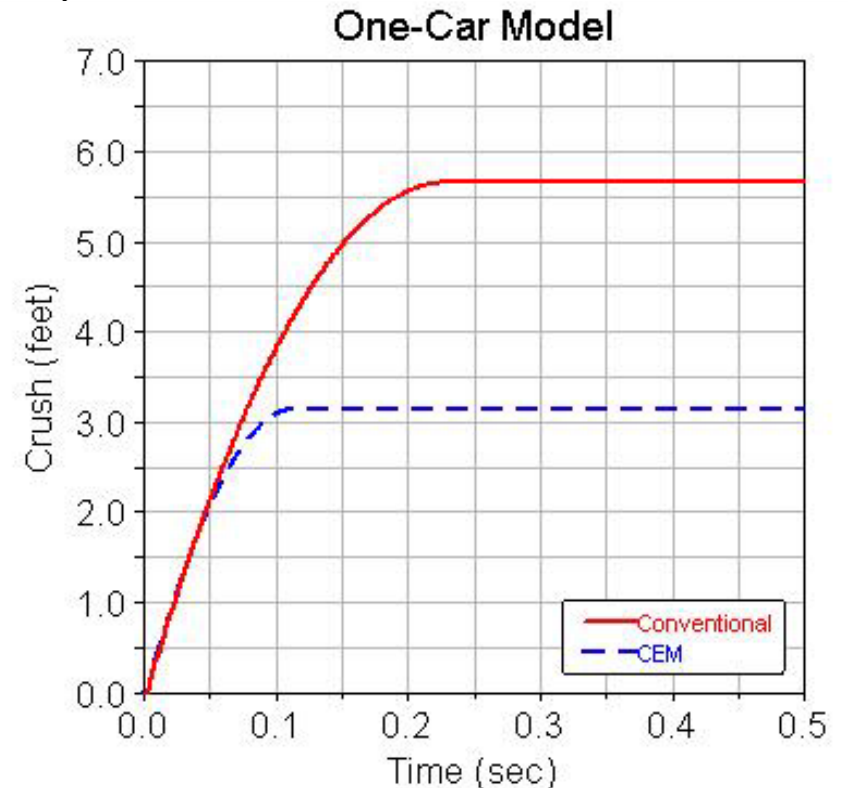

Figure 2. Car Crush from One-Car Model
The occupant's velocity relative to the vehicle governs the severity of the secondary impact. Generally, the relative velocity increases with the distance traveled. The higher the SIV, the greater the likelihood of occupant injury. A comparison of SIV for the conventional and CEM designs, shown in Figure 3, suggests the trade-off in performance associated with the higher average accelerations in the CEM design. At 2.5 feet of travel, the SIV is $22.5 \mathrm{mph}$ for the conventional design and $34 \mathrm{mph}$ for the CEM design. The CEM case has an SIV nearly equal to the impact velocity because the car is already rebounding off the rigid wall when the occupant strikes the forward seat back. Both of these cases are so severe that they would likely result in serious or lifethreatening injuries to the occupants.

Relative impact velocity is used here as a simple measure to compare the severity of different collisions with different crash pulses. It is not meant to predict the degree of injury severity or fatality for occupants exposed to a particular environment. For a more accurate identification of actual forces and accelerations likely to be experienced by occupants in a collision, it is necessary to review the data collected by the instrumented test dummies $[9,10,11]$.

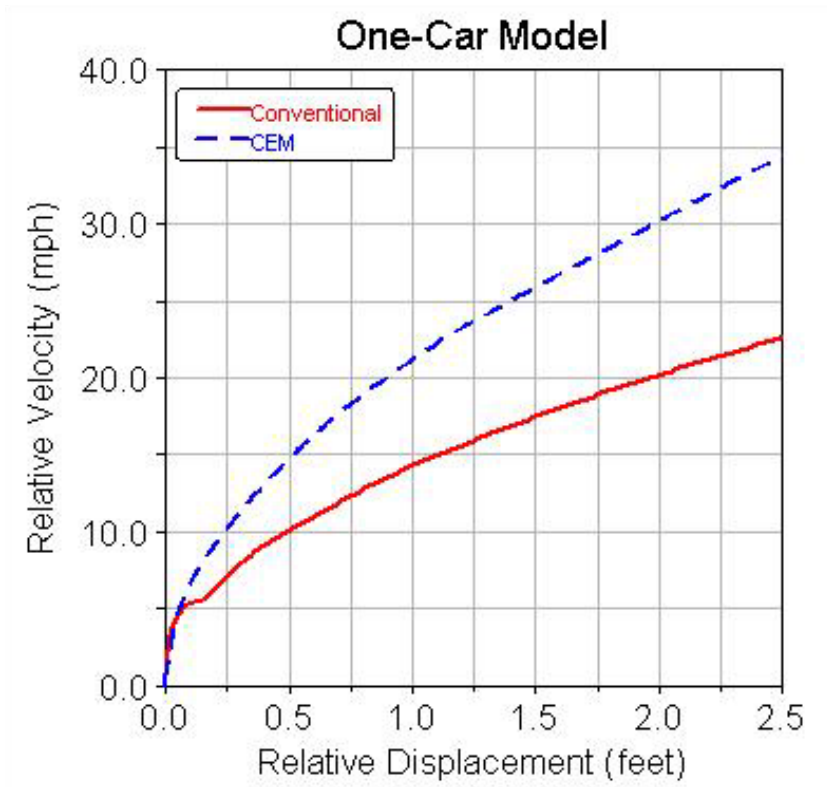

Figure 3. Secondary Impact Velocity from One-Car Model

\section{$\underline{\text { Two-Car Test }}$}

The car crush is depicted in Figure 4 for the two-car conventional and CEM models. The crush is plotted separately for the front and rear end of the leading car, and the front end of the trailing car. In the conventional model, nearly all the crush is isolated at the point of impact, with only inches being absorbed at the coupled connection between the cars. This occurs because of the large force required to initiate collapse of the structure. 


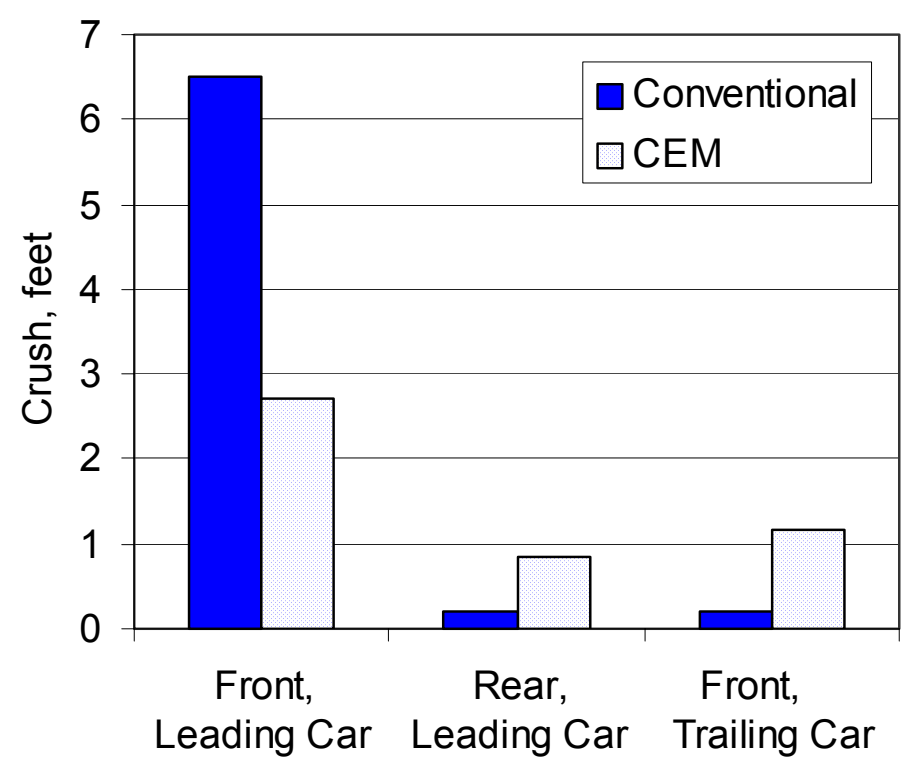

Figure 4. Car Crush from Two-Car Models

In contrast, the CEM design is able to distribute the crush between both cars, incurring 2.7 feet of damage at the front end of the leading car, and about a foot of damage to each car at the coupled connection. The CEM design allows crush to be shared with trailing cars by virtue of the tiered force/crush behavior. The occupant volume has been preserved in the CEM equipment while $3 \frac{1}{2}$ feet of occupant volume has been crushed in the conventional equipment. This amount of crush would destroy at least the first row of passenger seats and possibly intrude into the second row.

The secondary impact velocity for occupants in both cars of the conventional and CEM models are plotted in Figure 5. The SIV for occupants in both conventional cars is about $16 \mathrm{mph}$, compared with an SIV of 22.5 and $30 \mathrm{mph}$ for occupants in the leading and trailing CEM cars, respectively. The trailing CEM car has an SIV higher than the impact velocity because the trailing car is already rebounding off the rigid wall when the occupant strikes the forward seat back.

The secondary collision environment in the two-car test is more severe in the CEM case. The greatest SIV penalty is in the leading cars. For both the conventional train and the CEM train, the mass of the trailing cars tends to reduce the SIV in the leading cars. In a conventional train, the SIV tends to be the same for all the passenger cars in the train, and reduces uniformly for increased train length. The SIV's for all the cars in the train-to-train test were between 5 and $8 \mathrm{mph}$ [11], while for the two-car test, the SIV's were for both cars were approximately $16 \mathrm{mph}$, as shown in Figure 5. In a CEM train, the SIV's are highest near the impacting end, and decrease incrementally for each of the trailing cars [12]. The SIV of the trailing cars is lower because of the cushioning effect of the leading cars. In a CEM train collision, an occupant in any of the cars behind the first two cars would have an SIV close to that of an occupant in a conventional train collision.

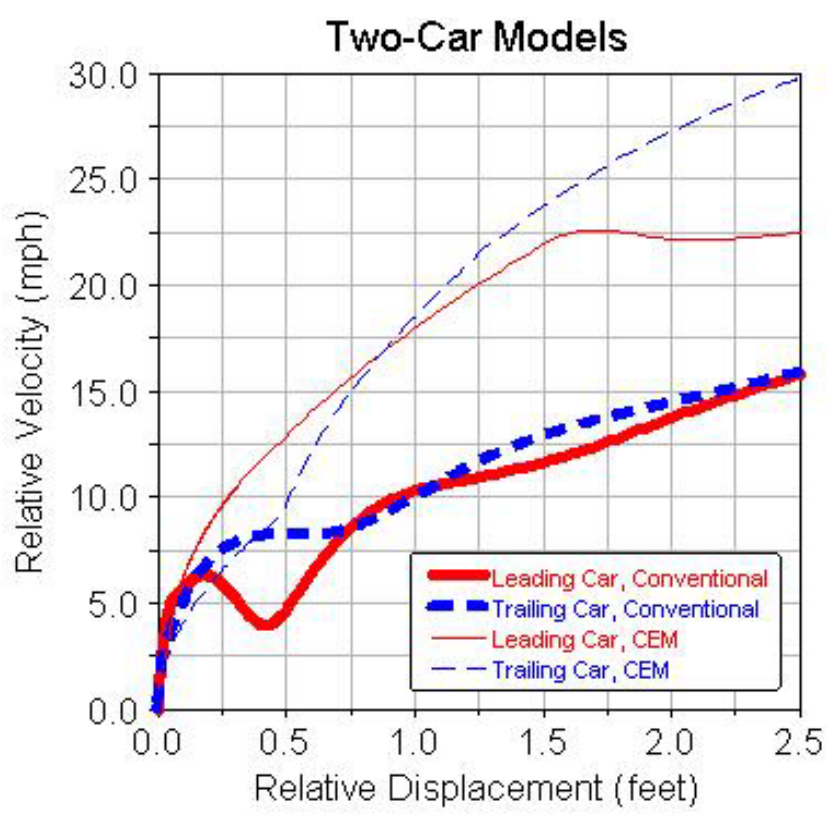

Figure 5. Secondary Impact Velocity from Two-Car Models

Figures 6 and 7 plot the lateral displacement measured at the ends of the coupled cars in the conventional and CEM twocar analyses, respectively. Saw-tooth lateral buckling was predicted to occur in the two-car conventional model, and it did occur during the test. Due to the design changes made in the modified CEM equipment, saw-tooth buckling is not predicted to occur in the two-car CEM model.

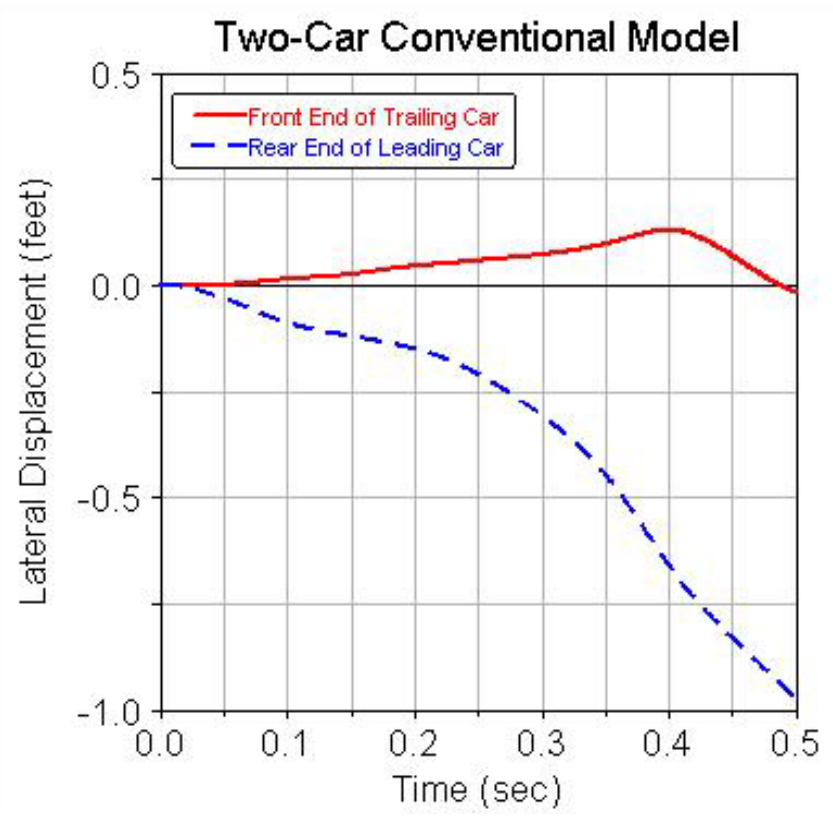

Figure 6. Lateral Displacement of Conventional Cars 


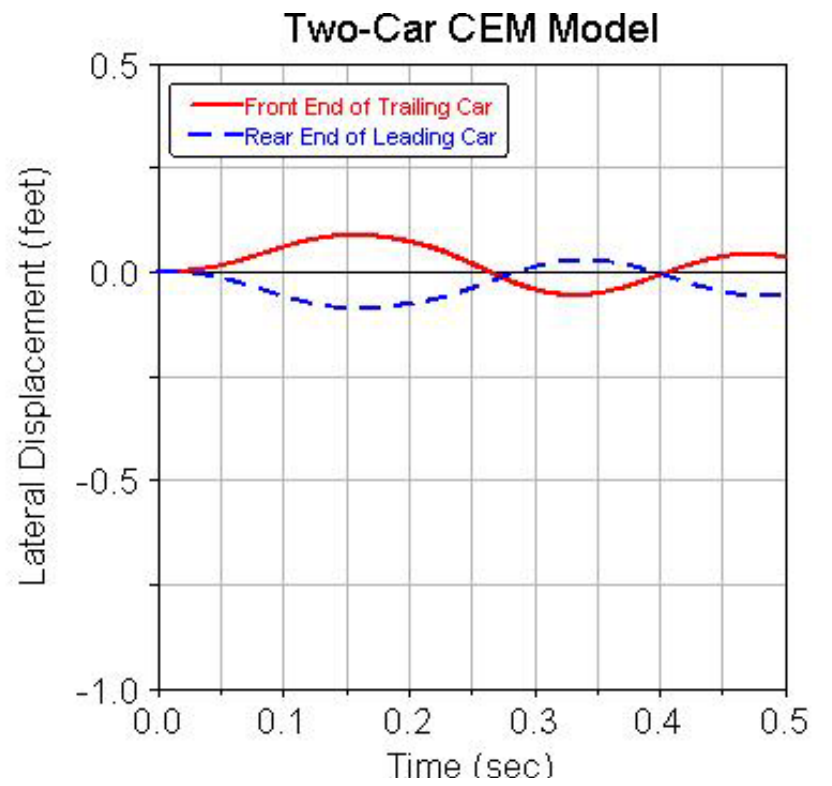

Figure 7. Lateral Displacement of CEM cars

The CEM car has a sliding sill that is designed to fail at a prescribed load and telescope in the draft pocket. This failure mode allows the car bodies to come in contact without producing the significant lateral loads that occur at the coupled interface in the conventional cars. Once buckling is initiated in the conventional design, the lateral displacement continues to increase. In the CEM design, there is not sufficient lateral motion for derailment or lateral buckling to occur.

\section{SUMMARY AND CONCLUSIONS}

The modeling results demonstrate that the CEM design is much more effective at preserving occupied volume during a collision. The monotonic increase in the CEM force/crush behavior cars allows the ends of the trailing cars to participate in energy absorption. The initial spike in the conventional force/crush behavior is what causes all the crush to be isolated at the impacting end of the conventional car test, crushing $21 / 2$ to 3 feet of occupant volume in the one- and two-car tests, respectively.

The trade-off in preserving the occupant volume in the CEM design is a higher SIV than with the conventional design in the one- and two-car tests. This penalty is most severe in the first car or two in train-to-train collision. This trade-off could possibly be mitigated by using rearward-facing seats in the leading car(s). Rearward-facing seats reduce the SIV because the occupant is already in contact with the vehicle, so the occupant doesn't develop a significant velocity with respect to the vehicle.

The results from the two-car CEM model establish the proof of concept by distributing the crush away from the point of impact. In addition to preserving the occupant volume, the CEM design can also help to keep the cars in line and avoid the dangers of lateral buckling and/or vertical override. The degree of damage in these large motion events is likely to be much greater than the in-line crush estimates.
The CEM models provide an intial estimate of the collision performance of modified CEM equipment. With proof of this concept established in the upcoming full scale tests, additional design improvements can be evaluated and simpler, less expensive component tests that measure energy dissipation. The influence on SIV can be calculated with validated CD models to quantify the improvement.

\section{ACKNOWLEDGMENTS}

The tests discussed in this paper were performed as part of the Equipment Safety Research Program sponsored by the Office of Research and Development of the Federal Railroad Administration. The authors would like to thank Dr. Tom Tsai, Program Manager, and Ms. Claire Orth, Division Chief, Equipment and Operating Practices Research Division, Office of Research and Development, Federal Railroad Administration, for their support. The authors would also like to thank Mr. Gunars Spons, Federal Railroad Administration Resident Engineer at the Transportation Technology Center, for managing the full-scale test effort, and Ms. Karina Jacobsen, mechanical engineer, Volpe Center, for making improvements to the collision dynamics models.

\section{REFERENCES}

[1] "SNCF Structural Crashworthiness Design Strategy Design Examples of Duplex TGV and XTER Diesel Multiple Unit," Rail Vehicle Crashworthiness Symposium, June 24-26, 1996, Cambridge, MA, DOT/FRA/ORD-97-08, pp. IIB-2-23 to IIB-2-56.

[2] Lewis, J.H., "Development of a Structural Specification for Crashworthy Rail Vehicles," 1995 ASME International Mechanical Engineering Congress and Exposition, AMD-Vol. 210, BED-Vol. 30, pp. 1-16.

[3] Lewis, J.H., "Validation of Measures to Improve Vehicle Safety in Railway Collisions," 1995 ASME International Mechanical Engineering Congress and Exposition, AMD-Vol. 210, BED-Vol. 30, pp. 17-34.

[4] Tyrell, D., Severson, K., Perlman, A.B., "Single Passenger Rail Car Impact Test Volume I: Overview and Selected Results," US Department of Transportation, DOT/FRA/ORD-00/02.1, March 2000.

[5] Tyrell, D., Severson, K., Perlman, A.B., "Passenger Rail Two-Car Impact Test Volume I: Overview and Selected Results," U.S. Department of Transportation, DOT/FRA/ORD-01/22.I, January 2002.

[6] Tyrell, D., Severson, K., Perlman, A.B., Rancatore, R., "Train-toTrain Impact Test: Analysis of Structural Measurements," American Society of Mechanical Engineers, Paper No. IMECE2002-33247, November 2002.

[7] Mayville, R., Johnson, K., Tyrell, D., "Development of a Rail Passenger Coach Car Crush-Zone," Proceedings of the 3rd International Symposium on the Passive Safety of Rail Vehicles, Berlin, March 21-22, 2002.

[8] Stevens, K.K., Statics and Strength of Materials, Prentice- Hall, Engelwood Cliffs, NJ, 1979.

[9] VanIngen-Dunn, C., "Single Passenger Rail Car Impact Test Volume II: Summary of Occupant Protection Program," U.S. Department of Transportation, DOT/FRA/ORD-00/02.2, March 2000.

[10] VanIngen-Dunn, C., "Passenger Rail Two-Car Impact Test Volume II: Summary of Occupant Protection Program," U.S. 
Department of Transportation, DOT/FRA/ORD-01/22.II, January 2002.

[11] Tyrell, D., Zolock, J. VannIngen-Dunn, C., R., "Train-to-Train Impact Test: Occupant Protection Experiments," American Society of Mechanical Engineers, Paper No. IMECE2002-39611, November 2002.

[12] Tyrell, D.C., Severson, K.J., Marquis, B.J., "Analysis of Occupant Protection Strategies in Train Collisions," American Society of Mechanical Engineers, AMD-Vol. 210, BED-Vol. 30, pp. 539-557, November 1995.

[13] ADAMS, Version 12.0, Mechanical Dynamics, Inc., Ann Arbor, Michigan.

[14] Severson, K., "Development of Collision Dynamics Models to Estimate the Results of Full-scale Rail Vehicle Impact Tests," Tufts University Master's Thesis, November 2000.

\section{APPENDIX A - MODELING APPROACH}

When developing the test requirements, $\mathrm{CD}$ models were developed to gather information about the likely test outcome. The test parameters were then determined based on the desired test results, that is a collision that was neither too benign nor too catastrophic. Test parameters to be determined included the impact velocity, the placement of accelerometers and strain gages, and the appropriate range of accelerometers to be used.

Separate models depicting the one- and two-car tests were developed using the Adams software program [13]. See Figure 8 for a schematic of the two-car model. The impacting car in both models consisted of four rigid masses that represented the front portion of the vehicle, the trucks and the main car body. A rigid coupler is connected to each car by a non-linear spring and damper. The model was capable of 3-D motion since each mass was allowed three translational and three rotational degrees of freedom. However, for this analysis the masses representing the front end and the main car body were constrained to translate longitudinally with respect to one another. Non-linear springs and dampers that represent the crushable end structure, the truck/car body suspension, and the coupler, were used to connect the masses. There is a friction force between the trucks and ground. There is also a lateral force between the trucks and ground that represents the wheel/rail contact. If the force exceeds a given threshold, derailment occurs. See Reference [14] for more detail about the conventional one- and two-car models.

The impact forces were transferred from the coupler/front plate to the main car body via five non-linear, longitudinal springs in parallel. These springs represent the force/crush behavior of the draft sill, two side sills and two roof sills. The model kept track of the current and maximum spring displacement. When unloading, the force in the springs followed the initial slope downward. If the springs were subsequently reloaded, the force followed the initial slope back up, then continued where it left off along the prescribed forcecrush curve.

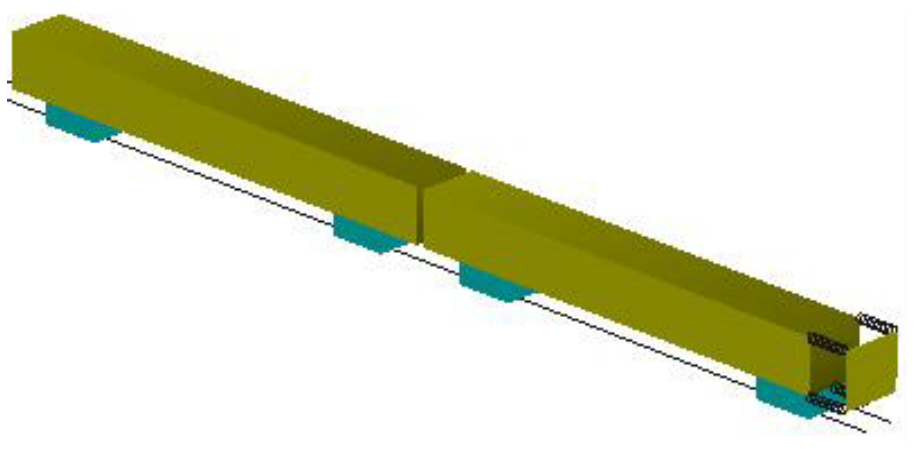

Figure 8. Schematic of Two-Car CD Model

The one- and two-car collision dynamics models were designed for a specific set of collision conditions. The applicable scenarios include in-line, frontal collisions with a rigid wall, at speeds up to approximately $50 \mathrm{mph}$. In these collision scenarios, the damage is expected to be limited to the 12-foot car length between the front of the car and the body bolster. The models do not account for structural crushing beyond the front body bolster, but could be modified to do so without much difficulty.

After both tests were completed, the models of the conventional equipment were fine-tuned to better agree with the test data. The lead car is identical in both models. In preparation for the modified equipment tests, the non-linear springs in the validated conventional models were modified to incorporate the CEM force-crush behavior.

\section{APPENDIX B - ADDITIONAL MODEL RESULTS}

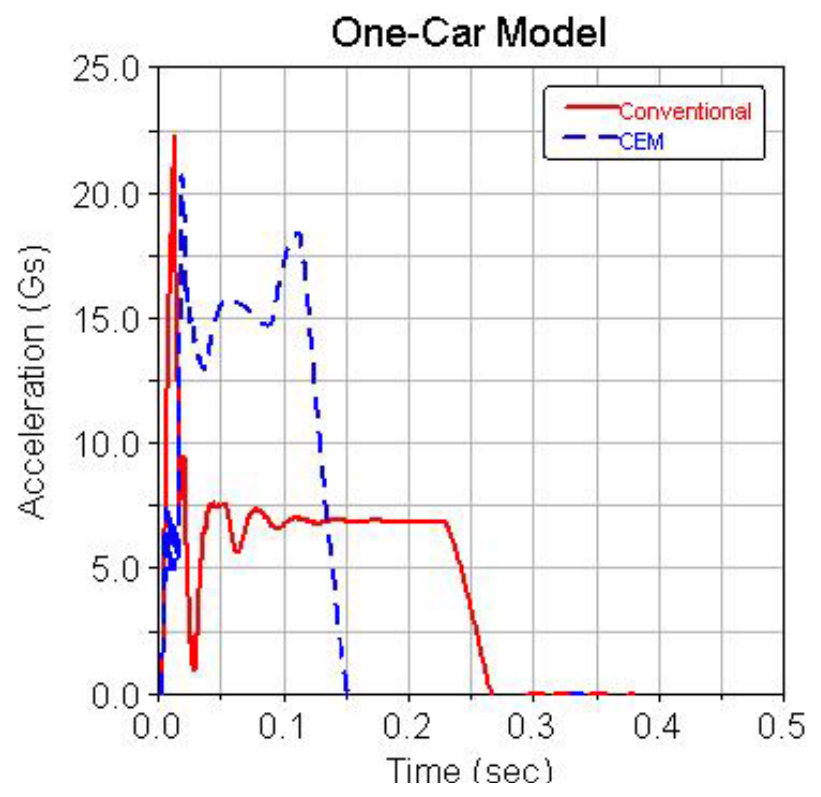

Figure 9. Acceleration-Time Histories from One-Car Models 


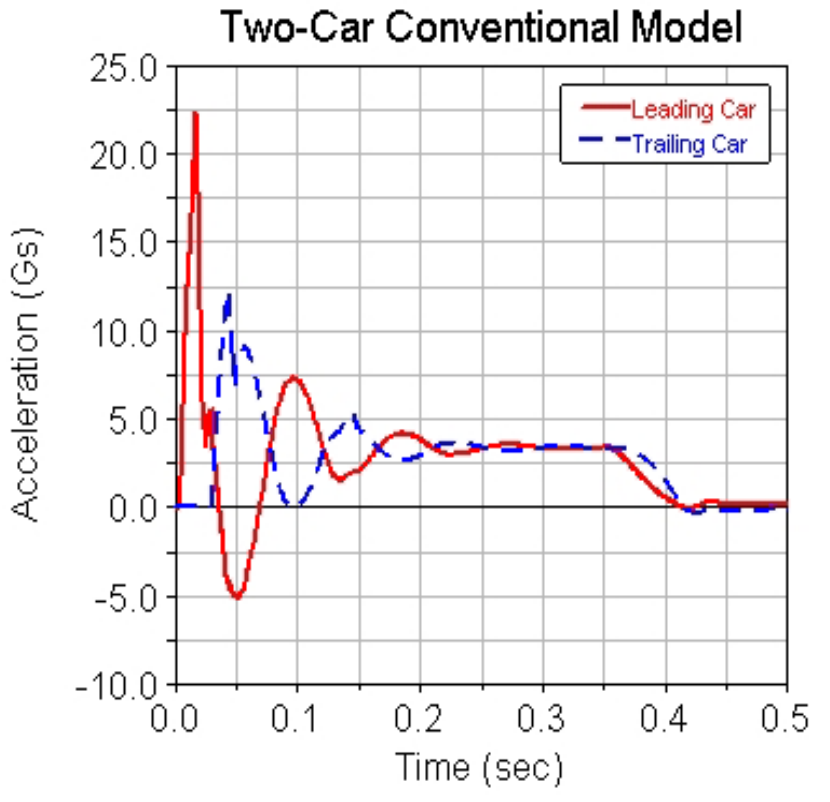

Figure 10. Acceleration-Time Histories from Two-Car Conventional Model

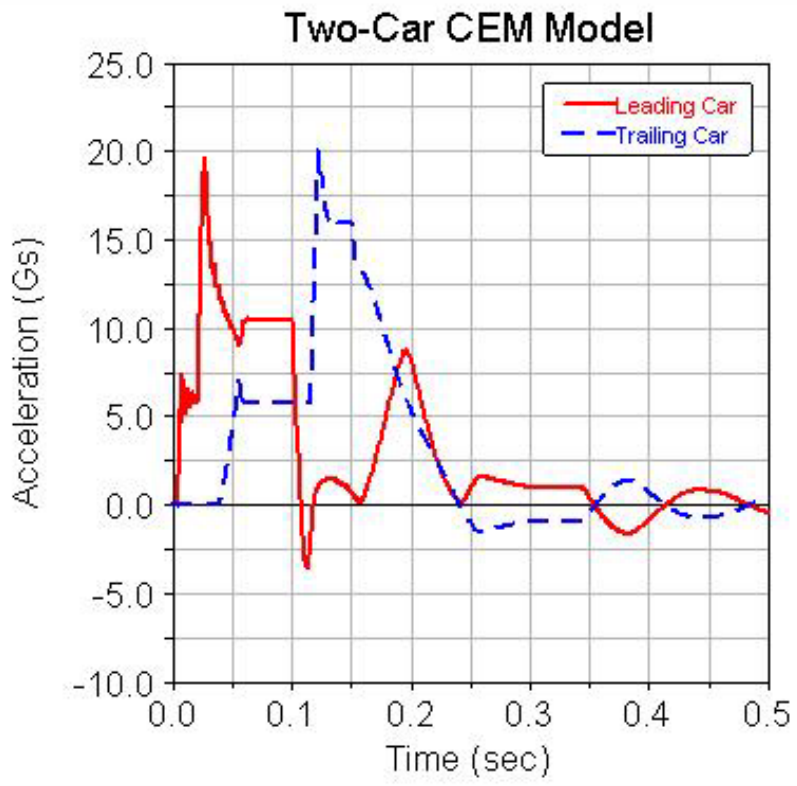

Figure 11. Acceleration-Time Histories from Two-Car CEM Model 